\title{
Acoustic segregation of Pinus radiata logs according to stiffness
}

\author{
A. Colin Matheson ${ }^{a^{*}}$, Ross L. Dickson ${ }^{\text {}}$, David J. Spencer ${ }^{\mathrm{a}}$, Bill Joe ${ }^{\mathrm{c}}$ and Jugo Ilic ${ }^{\mathrm{d}}$ \\ ${ }^{\text {a }}$ CSIRO Forestry and Forest Products, PO Box E4008, Kingston, ACT 2604, Australia \\ ${ }^{\mathrm{b}}$ State Forests of New South Wales, Research and Development Division, PO Box 46, Tumut, NSW 2720, Australia \\ ${ }^{\mathrm{c}}$ State Forests of New South Wales, Research and Development Division, PO Box 100, Beecroft, NSW 2119, Australia \\ ${ }^{\mathrm{d}}$ CSIRO Forestry and Forest Products, Private Bag 10, Clayton South MDC, Clayton, VIC 3169, Australia
}

(Received 16 August 2001; accepted 17 May 2002)

\begin{abstract}
Wood stiffness varies enormously both within and between trees, so it is inevitable that low-grade solid wood products are produced from some trees. Accordingly, it would be highly desirable to segregate logs to ensure that only those logs with predominantly high stiffness wood are processed into structural lumber products. This study examined whether sound flight velocity ( $\mathrm{m} \mathrm{s}^{-1}$ ) could be used as a direct measure of wood stiffness to allow such segregation. Trees of radiata pine were measured before and after harvest with a non-destructive acoustic device (stress wave timer) to see if there was a relationship between sound wave velocity in either standing trees or logs and machine stress-grades of boards derived from those trees and logs. The speed of sound along logs was sufficiently closely correlated with wood stiffness to allow logs to be sorted into classes. A highly significant and positive relationship was found for acoustic measurements made in logs and a weaker, but still significant, relationship existed for acoustic measurements made in standing trees. Such segregation of logs according to wave velocity measured in the field may save a large sawmill between A $\$ 1-4 \mathrm{~m}$ each year. Acoustic methods may also be used as an indirect tool for selection provided the heritability of the measurements is high enough and there is significant genetic correlation with genetic values for wood stiffness. From another experiment we have estimated the heritability of several acoustic measures and hope to be able to estimate genetic relationships with wood quality soon.
\end{abstract}

modulus of elasticity / wood, acoustics / sound speed / selection

Résumé - Classement des grumes de pin radiata selon le module d'élasticité par méthode acoustique. Les variations de module d'élasticité du bois, aussi bien inter- qu'intra- arbre peuvent être considérables. Il est alors inévitable de trouver des pièces de qualité mécanique médiocre en scierie. Il serait donc tout à fait souhaitable de pouvoir classer les grumes de telle sorte que seules celles qui pourront donner des sciages de qualité soient orientées pour la production de bois d'œuvre. Cette étude analyse la possibilité d'utiliser la vitesse de propagation du son dans le bois comme estimateur du module d'élasticité permettant un tel classement. Plusieurs pins radiata ont été mesurés avant et après abattage par une méthode non destructive afin d'analyser la relation entre la vitesse du son mesurée dans l'arbre sur pied ou la grume d'une part, et le classement mécanique sur machine des planches issues de ces grumes d'autre part. La corrélation positive et très significative mesurée sur grume est suffisamment élevée pour permettre le classement de ces grumes. Cette corrélation est plus faible, mais reste significative pour les mesures effectuées sur pied. Un classement des grumes effectué de cette façon sur chantier permettrait à une scierie de grande taille d'économiser de 1 à 4 millions de dollars australiens chaque année. Les méthodes acoustiques pourraient aussi être utilisées comme outil indirect pour la sélection génétique d'arbres de haute qualité mécanique, pourvu que l'héritabilité soit suffisante. Dans une autre série d'expérimentations l'héritabilité de plusieurs mesures acoustiques a été estimée et la liaison génétique/qualité du bois sera examinée.

module d'élasticité / bois, acoustique / vitesse de son / sélection

\section{INTRODUCTION}

Wood stiffness and strength varies greatly between and within stands of Pinus radiata and this offers an opportunity to improve the way logs are sorted at harvest time and allocated to processors to optimise the value of lumber recovered. One way of achieving this is to allocate wood with predominantly high stiffness properties to structural markets and wood that does not meet this criterion to reconstituted wood

* Correspondence and reprints

Tel.: +612 62818322; fax: 612 62818312; e-mail: colin.matheson@ csiro.au 
manufacturers [15]. Currently, wood supplies are sorted at harvest only to a limited extent by using surrogate indicators, such as log size, the number and size of knots, straightness, etc. that are not closely correlated with wood stiffness or strength.

However, it is possible to use sound wave technologies to assess the mechanical properties of timber more directly [4, $12,13]$. There is a strong relationship between stiffness of $\operatorname{logs}$ (measured acoustically) and mean stiffness of boards cut from the $\operatorname{logs}$ (measured using transverse vibration techniques) in Balsam fir $(r=0.57)$ and White spruce $(r=0.91)$ $[11,12]$.

Nakamura and Arima [8] reported a good relationship between stiffness and the square of the wave velocity for standing trees across a range of stands. They calculated the Modulus of elasticity (MoE) from wave velocity as; $\mathrm{MoE}=\mathrm{v}^{2} \times \rho / \mathrm{g}$, in which $\mathrm{v}$ is the sonic velocity, $\rho$ is the density and $\mathrm{g}$ is acceleration due to gravity $\left(=980 \mathrm{~cm} \mathrm{~s}^{-1}\right)$.

There are numerous reports of a strong relationship between sound velocity and stiffness of logs, but stiffness was usually determined under controlled laboratory conditions for clearwood. Few studies have examined the relationship between acoustic sound velocity and machine stress grades, which take into account the effect on stiffness of branch knots and defects both of which reduce stiffness and strength [13, 14].

Walker and Nakada [15] showed that acoustic measurements allowed the sorting of Pinus radiata logs according to stiffness. Clearly, it would be desirable to have a method of estimating stiffness for resource evaluation and for genetic selection before harvest, i.e. non-destructively. However, there are only a few reports that relate standing tree and log acoustic measurements to machine stress grades of boards sawn from them. Nevertheless, this study shows that quick and non-destructive acoustic measurements can be used as a direct measure of wood stiffness in either standing trees or $\operatorname{logs}$ of radiata pine. Ultimately, this should lead to a more efficient use of the resource by directing the timber of varying quality to the appropriate market.

\section{MATERIALS AND METHODS}

144 trees of Pinus radiata D. Don were selected from an experimental plantation for the main part of the study. The trees were measured acoustically while standing, and then cut into the maximum number of merchantable logs possible (up to six) during harvesting. A total of $535 \log$ s were cut from the 144 trees. Log lengths were determined by the harvester operator as if the harvest was a normal operation. Log butts were painted with colour combinations to permit tree, $\log$ and board identification. Individual logs were then measured acoustically and sawn into boards. The sawing pattern, and consequently the board sizes, were determined by the sawmill to maximize return and depended primarily on log size and produced a total of 4517 boards. $36 \%$ of the boards were $70 \mathrm{~mm} \times 35 \mathrm{~mm}$ and $33 \%$ were $90 \mathrm{~mm} \times 35 \mathrm{~mm}$ in cross section. The remainder were
$90 \mathrm{~mm} \times 45 \mathrm{~mm}, 70 \mathrm{~mm} \times 45 \mathrm{~mm}$, and a small proportion of $100 \mathrm{~mm} \times 80 \mathrm{~mm}$. Boards were kiln dried, dressed and machine stress graded following which the stress grade of each board was recorded.

The experimental plantation was Progeny Test 51 (PT51), planted in June 1970 in Compartment 19, Tallaganda State Forest, NSW. There were two seedlots; one was a bulked collection from the first-generation Tallaganda Seed Orchard and the other an unselected control. The experiment had been thinned to 350 stems per hectare in 1978. Earlier results from the experiment are described in $[3,6,7]$. Two plots of each seedlot in each of four replicates were available for this study.

For the genetical part of the study, 260 trees in an adjacent experiment called Progeny Test 56 (PT56) were used. Trees in this experiment were from a structured set of 24 families with 10 parents represented and were propagated as cuttings from two-year-old stock and planted in 1973. Approximately half of the experiment was thinned at age 10 to $50 \%$ stocking. There were 6 replicates of single-tree plots planted as randomised complete blocks. Trees were measured acoustically using three different tools (FAKOPP and two other proprietary instruments - see below). FAKOPP was used on standing trees and all three methods used on the first log from each tree. Other facets of the methodology were the same as for PT51.

\subsection{Sampling strategy}

In PT51, the nine innermost trees in each of the 16 plots were selected for this study. The experiment was damaged by a windstorm just before the measuring and harvesting operations and a few of the sample trees were blown over but not damaged. Tree numbers running from 1 to 144 were blazed on sample trees before the harvesting began. Following harvesting, each log was numerically coded incorporating the tree number so that logs could be identified. Logs were transported to the sawmill's log yard where each log was colour coded, measured acoustically and for length and diameter before being sawn. Log length within each tree was used to identify the log's position in the crown.

PT56 was treated very similarly in that trees were labelled numerically before acoustic measurements were taken on the standing trees. The trees were harvested and acoustic measurements taken using three acoustic tools on the first log from each tree. These first logs were later processed into boards in a sawmill where they were mechanically graded. The results on boards are to be reported elsewhere.

\subsection{Stress Wave Timing (SWT) measurements}

For PT51 all of the SWT measurements in the standing trees and logs were recorded using a FAKOPP microsecond timer. This instrument comprised two probes, namely a transmitting accelerometer inserted into the tree stem $0.5 \mathrm{~m}$ above the ground, and a receiving accelerometer inserted into the wood $1 \mathrm{~m}$ above this on the opposite side of the stem. Tapping the transmitter with a hammer induces the stress waves detected by the receiver and the flight time of the initial wavefront is calculated, based on the distance between the transmitter and the receiver. The receiver detects the initial part of the stress wave, which may travel through the heart of the tree (where the flight time is expected to be least) or may travel around the tree in the stiffer sapwood (where the flight time is expected to be greatest).

Longitudinal stress wave measurements were also made on individual logs in the sawmill yard soon after harvest by inserting the 
transmitting accelerometer into one end of the log and the receiving accelerometer in the other end. As for the standing tree measurements, the stress waves were propagated by tapping the transmitting accelerometer and recording sound flight time.

For PT56, the FAKOPP measurements were carried out as in PT51. Acoustic measurements were also made by two instruments which measure resonance in a frequency spectrum. These two instruments were; a resonance tool under development by CSIRO, and Hitman $^{\circledR}$ owned by Carter Holt Harvey Ltd. They were used only on the logs as they require a cut face to measure at one end of a log the frequency of the generated wave returning from the other end of the $\log$ when the cut face is struck.

\subsection{Machine stress grade}

Heartwood and sapwood boards were kiln dried, dressed and then stress-graded by machine (Metriguard CLT for PT51, Eldeco DART for PT56) during which dyes were sprayed on boards continuously to indicate the stress grade at any point along the board. The Metriguard machines operate on the principle of measuring the load to produce a standard deflection, the DART machines work by measuring the deflection in response to a standard load. One Metriguard machine was used for PT51 and two parallel DART machines were used for PT56. The stiffness grades produced by the two DART machines did not differ significantly. Boards of different dimensions were tested in batches with the stress grade machines being adjusted to take dimensional differences into account in producing the grades. Stress grades were recorded in $10 \mathrm{~cm}$ lengths along every board. Stiffness grades were the Machine Graded Pine (MGP) grades 10, 12 and 15, corresponding to average Moduli of Elasticity of 10000,12700 and $15200 \mathrm{MPa}$ respectively [9, 10]. In calculating the average, it was assumed that these stiffness grades were on a linear scale. To these MGP grades were added the equivalent of the former grade F4 (just below minimum structural grade requirements), which we gave an arbitrary MGP value of 9; reject material was given the arbitrary MGP value of 0 . Minimum stiffness grade was the least grade on each board and was used in calculating the monetary value of each board.

\subsection{Analysis}

Weighted average and weighted minimum stiffness grades for trees and logs within trees were obtained from measurements on individual boards. Stress wave time measurements as recorded by the FAKOPP stress wave timer on both standing trees and individual logs were converted to wave velocities. Analyses of variance were carried out on PT51 data from each board by fitting the following linear model:

$\mathrm{Y}_{i j k l}=\mu+$ replicate $_{i}+$ seedlot $_{j}+\log _{k}+$ seedlot.tree $_{j l}+$ error

In which there were 4 replicates (i.e. $i=1 \ldots 4)$, two seedlots $(j=1,2)$ and 9 trees per seedlot in each replicate (i.e. $l=1 \ldots 9)$. In model (1), logs were numbered from the butt $(k=1)$ upwards to a maximum of $k=6$ and the mean was estimated by $\mu$.

For PT56, analysis of variance was carried out on the measurements from the three acoustic instruments. Thinning was accounted for by fitting a dummy variate. Genetic effects were estimated using least squares and equating expected mean squares to their expectation using the Fortran program DIALL. Standard errors were estimated according to Kempthorne [5]. The linear model fitted was:

$\mathrm{Y}_{i j k l}=\mu+$ thinning $_{i}+$ replicate $_{j}+{\text { general combining } \text { ability }_{k}+\text { spe- }}$ cific combining ability $_{k l}+$ error $_{i j k l}$
In which there were two thinning regimes (i.e. $i=1,2$ ), there were up to 6 replicates (i.e. $j=1 \ldots 6)$, there were 9 parents (i.e. $k=1 \ldots 9)$ and up to 4 crosses per parent (i.e. $l=1 \ldots 4)$.

Heritability $\left(\mathrm{h}^{2}\right)$ was calculated from the estimates of general (gca) and specific (sca) combining ability effects as follows:

$$
\mathrm{h}^{2}=\frac{4 \mathrm{~V}_{\text {gca }}}{2 \mathrm{~V}_{\text {gca }}+\mathrm{V}_{\text {sca }}+\mathrm{V}_{\mathrm{e}}}
$$

where $\mathrm{V}_{\text {gca }}, \mathrm{V}_{\text {sca }}$ and $\mathrm{V}_{\mathrm{e}}$ are variance components for gca, sca and residual, respectively.

Genetic correlations were estimated as the Pearson correlation between breeding values $(2 \times$ gca effect + experimental mean $)$ for each parent and trait.

\section{RESULTS}

\subsection{Wave velocities in standing trees and logs}

The effect of the windstorm in blowing down some trees was found to be negligible on acoustic wave velocities and so this factor was not considered further.

Stress wave velocities in trees before harvest were lower than for cut logs. This is not surprising, as wave velocity must be affected by the mass of the tree when standing, and the wave is propagating across growth layers as opposed to along growth layers in a longitudinal direction. We do not believe there is any effect of soil or roots since they do not lie between the transmitter and detector. The regression equation between wave velocities in standing trees and the means of all $\log$ s cut from each tree was (figure 1 ): velocity in $\operatorname{logs}=2.5+$ $0.59 \times$ velocity in trees.

The correlation between the two variables was 0.58 $(P<0.001)$ and was very similar for both seedlots. The correlation between velocities in standing trees and in the first log was slightly less than for all $\operatorname{logs}(0.53, P<0.001)$, perhaps because it is based on a single acoustic measurement rather than being the mean of up to six.

\subsection{Machine Stress Grade (MGP grade units)}

Average stress grade per log (i.e. the average over all boards in each log) varied from 9.08 to 13.92, averaging 11.25. Average minimum stress grade per log (i.e. the average minimum per board) varied from 0 (rejected as a structural board) to 12.38 averaging 9.33. Although non-integer stiffness grades have no market meaning, higher averages indicate greater proportion of the higher grades.

The two seedlots were highly significantly different for average stiffness and significantly different for minimum stiffness (tables I, II). Boards from seed orchard-derived trees had lower average stiffness than boards from control trees, but greater minimum stiffness. The difference between average and minimum stiffness is interpreted as the effects of defects. In many boards the minimum stiffness portion is associated with knots or juvenile wood (see [1]). These results 


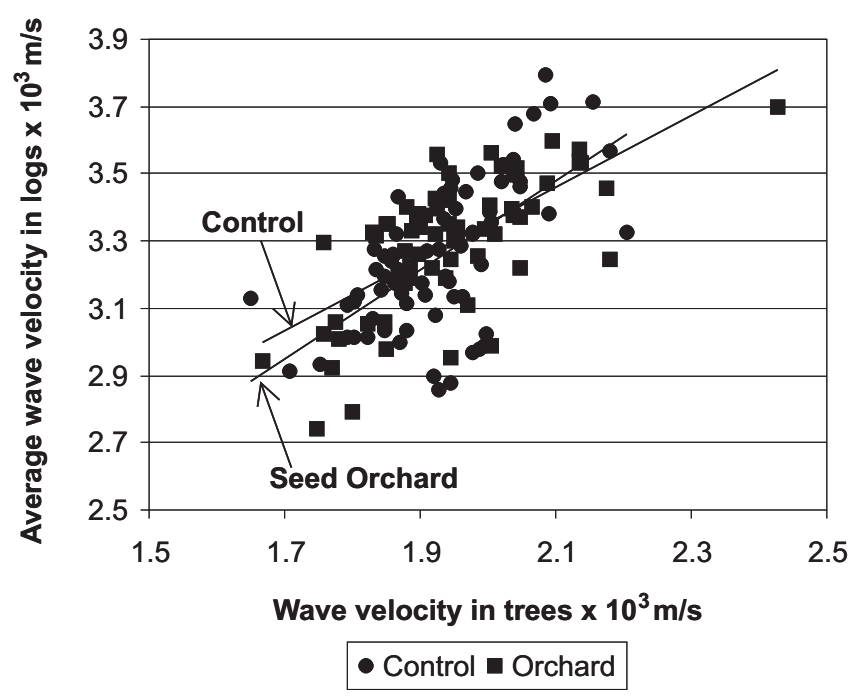

Figure 1. Comparison between wave velocities in standing trees and those in cut logs. Each data point represents the average of two measurements for standing trees and represents the average of both measurements over all logs in a tree for cut logs.

Table I. Summarised analyses of variance for average board strength and minimum board stiffness. Average MGP grade refers to the grade averaged over all measured parts of each board, minimum MGP grade is the lowest grade found in each board.

\begin{tabular}{lccc}
\hline $\begin{array}{l}\text { Source } \\
\text { of variation }\end{array}$ & df & $\begin{array}{c}\text { Mean Square } \\
\text { (Average MGP grade) }\end{array}$ & $\begin{array}{c}\text { Mean Square } \\
\text { (Minimum MGP grade) }\end{array}$ \\
\hline Replicates & 3 & $4.95^{*}$ & $31.32^{*}$ \\
Seedlot & 1 & $14.99^{* *}$ & $39.37 *$ \\
Log & 6 & $83.42^{* * *}$ & $45.65 * * *$ \\
Tree within seedlot & 96 & $11.14 * * *$ & $26.98^{* * *}$ \\
Residual & 4249 & 1.72 & 8.63 \\
\hline
\end{tabular}

* significant at $P=0.05, * * P=0.01, * * * P=0.001$.

Table II. Weighted and unweighted seedlot means for average board strength and minimum board stiffness. Weighted means were obtained by weighting for volume of each board. Average and minimum stiffness as in table $I$.

\begin{tabular}{lcccc}
\hline Seedlot & \multicolumn{2}{c}{ Average board stiffness } & \multicolumn{2}{c}{ Minimum board stiffness } \\
\hline & Weighted & Unweighted & Weighted & Unweighted \\
\cline { 1 - 2 } $\begin{array}{l}\text { Tallaganda } \\
\text { Seed Orchard }\end{array}$ & 11.329 & 11.314 & 9.474 & 9.440 \\
\begin{tabular}{l} 
Control \\
\hline
\end{tabular} & 11.438 & 11.429 & 9.261 & 9.239 \\
\hline
\end{tabular}

indicate that boards from control trees had more defects than orchard-derived boards.

There were also differences between trees within seedlots and between $\log$ numbers. Means for each log are given in table III in which it is clear that there is a general decrease in board stiffness as $\log$ number increases except for $\log 5$ which for both stiffness traits had higher stiffness than $\log 4$.
Table III. Means for each log for average board strength and minimum board stiffness.

\begin{tabular}{lcc}
\hline Log & $\begin{array}{c}\text { Average board } \\
\text { stiffness }\end{array}$ & $\begin{array}{c}\text { Minimum board } \\
\text { stiffness }\end{array}$ \\
\hline 1 & 11.696 & 9.605 \\
2 & 11.313 & 9.210 \\
3 & 11.076 & 9.242 \\
4 & 10.798 & 9.052 \\
5 & 10.872 & 9.468 \\
Standard error of difference & 0.068 & 0.152 \\
\hline
\end{tabular}

This is particularly pronounced for minimum stiffness where $\log 5$ was not significantly different from $\log 1$.

\subsection{Relationships between wave velocity and board stiffness}

At the log level there was a highly significant relationship between average board stiffness and wave velocity $(\mathrm{r}=0.50$, $P<0.001$ ), but that between minimum board stiffness and wave velocity was weaker $(\mathrm{r}=0.34, P<0.001)$. This difference is probably caused by some boards and even whole logs with a minimum stiffness grade of 0 caused by defects, although their average may have been much greater. There was no significant difference in the correlations between stiffness and velocity for logs of the two seedlots.

At the tree level there was a significant relationship between average board stiffness and wave velocity measured in standing trees for the control seedlot $(\mathrm{r}=0.33$, $0.01<P<0.001)$. Unexpectedly however, there was no significant correlation for the orchard seedlot $(r=0.01, n s)$.

\subsection{Extra revenue from log segregation?}

There is clearly a relationship between wave velocity measured on logs and average board stiffness. Although the correlation is nowhere near perfect, it does not need to be, and segregating logs based on wave velocity should improve the quality of logs passing through a sawmill resulting in product being sold for a higher price.

Attempting to quantify what the extra value might be for a sawmill, we calculated the value of each board based on industry prices in $\mathrm{A} \$$ for boards of given minimum stiffness. We simulated log segregation arbitrarily at $3.77 \times 10^{3} \mathrm{~m} \mathrm{~s}^{-1}$ by calculating the value per cubic metre of the material from logs with FAKOPP readings greater than this. The results are presented in figure 2 where the value of the timber with greater readings was $\$ 385.30 \mathrm{~m}^{-3}$ compared with a value of the whole set of $\$ 379.26 \mathrm{~m}^{-3}$. This difference of $\$ 6.04 \mathrm{~m}^{-3}$ represents the extra revenue obtained from segregating logs at $3.77 \times 10^{3} \mathrm{~m} \mathrm{~s}^{-1}$. For a mill capacity of $600000 \mathrm{~m}^{3} \mathrm{y}^{-1}$, this extra revenue would be $\$ 3624000 \mathrm{y}^{-1}$. An analysis based on sawmill outturn is given below. 


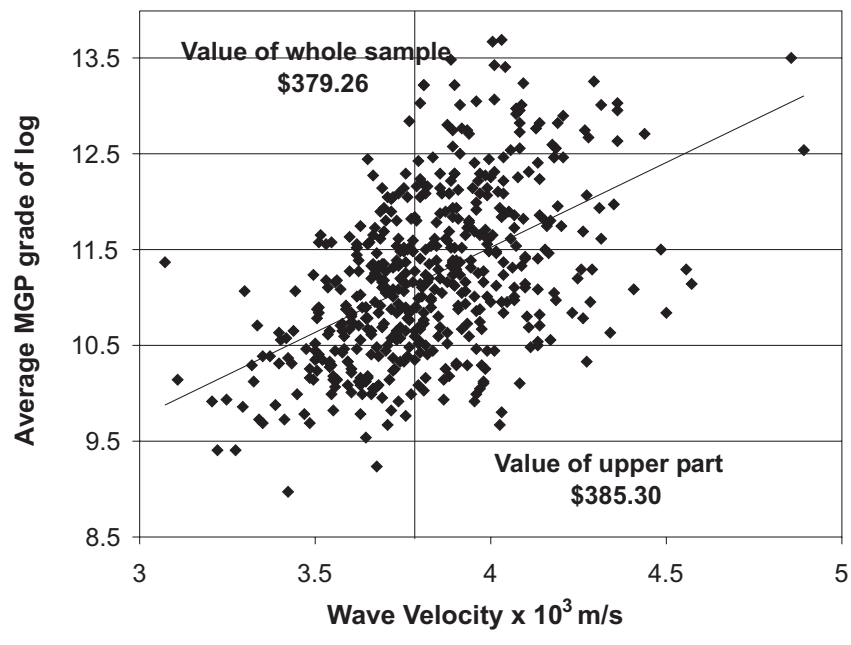

Figure 2. Value of $\log$ segregation at $3.77 \times 10^{3} \mathrm{~m} \mathrm{~s}^{-1}$. Each data point represents a single log.

\subsection{Financial implications}

We assumed that segregation takes place in the forest based on acoustic measurements on logs during harvest and, making calculations on units of 100 ha, we assume that harvesting yields $450 \mathrm{~m}^{3} \mathrm{ha}^{-1}$. We estimate that extra labour costs $\$ 12500$ for the total area and extra machine costs to be $\$ 16500$ (table IV). Over a total yield of $45000 \mathrm{~m}^{3}$ the extra cost of segregating logs would be $\$ 0.64 \mathrm{~m}^{-3}$ plus a negligible
Table IV. Calculations to estimate the cost of log segregation. It is assumed that for 100 ha of softwood pine forest the yield is $450 \mathrm{~m}^{3} \mathrm{ha}^{-1}$ of fibre which takes 50 days to harvest. That the extra excavator time required to segregate the logs is 10 minutes/hour.

\begin{tabular}{|c|c|c|}
\hline Item & Item value & Notes \\
\hline 1 harvest unit & $100 \mathrm{ha}$ & \\
\hline Total volume & $45000 \mathrm{~m}^{3}$ & $450 \mathrm{~m}^{3} \mathrm{ha}^{-1}$ \\
\hline Harvest days & 50 days & 2 ha/day \\
\hline Wages/day & $\$ 250$ & 1 operator - forest hanc \\
\hline Total wage bill & $\$ 12500$ & \\
\hline Excavator & $\$ 1000 /$ day & Hire cost \\
\hline Hourly rate & $\$ 125 /$ hour & \\
\hline Extra time per $\mathrm{m}^{3}$ & 0.33 hours & $\begin{array}{l}\text { extra time to allocate } \\
\text { logs to different classes }\end{array}$ \\
\hline Extra machine cost & $\$ 41 /$ hour & \\
\hline Total & $\$ 16500$ & \\
\hline Cost $\mathrm{m}^{-3}$ & $\$ 0.64 \mathrm{~m}^{-3}$ & \\
\hline
\end{tabular}

capital cost of equipment and minus some transport costs. For a mill capacity of $600000 \mathrm{~m}^{3} \mathrm{y}^{-1}$, this extra cost would be $\$ 386667 \mathrm{y}^{-1}$, very small compared with the extra revenue.

Our estimate of $\$ 6.04 \mathrm{~m}^{-3}$ extra revenue is based on crude prices for different stiffness boards. It is possible to sharpen the estimate by examining possible changes to the mix of product from the sawmill. In calculations outlined in table IV, we considered three options (table $V$ ):

Table V. Benefit-costs analysis for three log segregation options. The first option is not to carry out log segregation. The second option $(3 \%<$ Merchant) is a light segregation leading to $2 \%$ extra revenue for MGP12, MGP10 and non-structural material allied with 3\% less revenue for Merchant material. The third option is a heavier segregation leading to 2.5\% more revenue than Option 2 for MGP12, MGP10 and non-structural material and $5 \%$ less revenue for Merchant material.

\begin{tabular}{|c|c|c|c|}
\hline & $\$ / \mathbf{m}^{3}$ & $\begin{array}{c}\$ / \mathbf{m}^{3} \\
(3 \%<\text { Merchant })\end{array}$ & $\begin{array}{c}\$ / \mathrm{m}^{3} \\
(5 \%<\text { Merchant })\end{array}$ \\
\hline $50 \%$ (F8, F5, non-structural) & $\$ 200.00$ & $\$ 204.00$ & $\$ 209.10$ \\
\hline $5 \%$ Case & $\$ 90.00$ & $\$ 90.00$ & $\$ 90.00$ \\
\hline $15 \%$ boards & $\$ 25.30$ & $\$ 25.55$ & $\$ 26.19$ \\
\hline 15\% Merchant & $\$ 33.00$ & $\$ 32.01$ & $\$ 30.41$ \\
\hline $10 \% \mathrm{~F} 7$ & $\$ 62.00$ & $\$ 62.00$ & $\$ 62.00$ \\
\hline 5\% Linings/mouldings, FJ, RSKD & $\$ 45.00$ & $\$ 45.00$ & $\$ 45.00$ \\
\hline Gross revenue per $100 \mathrm{~m}^{3}$ & $\$ 455.30$ & $\$ 458.56$ & $\$ 462.70$ \\
\hline Merchantable costs & $\$ 150.00$ & $\$ 150.00$ & $\$ 150.00$ \\
\hline Mill to $\log$ cost & $\$ 172.97$ & $\$ 172.97$ & $\$ 172.97$ \\
\hline Net revenue & $\$ 132.33$ & $\$ 135.59$ & $\$ 139.73$ \\
\hline \multicolumn{4}{|l|}{ Financial analysis } \\
\hline Cost of log segregation $/ \mathrm{m}^{3}$ (assumption) & $\$ 0.64$ & $\$ 0.64$ & $\$ 7.40$ \\
\hline Benefit in outturn & & $\$ 3.26$ & \\
\hline $\mathrm{Net} / \mathrm{m}^{3}$ & & $\$ 2.62$ & $\$ 6.76$ \\
\hline Total volume of sawlogs $\left(\mathrm{m}^{3}\right) / \mathrm{yr}$ & & 600000 & 600000 \\
\hline Total net benefits to sawmill/yr & & $\$ 1573800$ & $\$ 4056795$ \\
\hline
\end{tabular}


Table VI. Heritabilities (standard errors) on the diagonal, genetic correlations (above the diagonal, standard errors in brackets) and phenotypic correlations (below the diagonal) among measurements from three different acoustic instruments.

\begin{tabular}{lcccc}
\hline & Fakopp (tree) & Fakopp $(\log )$ & Hitman $^{\circledR}(\log )$ & CSIRO $(\log )$ \\
\hline Fakopp $($ tree $)$ & $\mathbf{0 . 1 6}(\mathbf{0 . 1 4})$ & $0.93(0.11)$ & $0.95(0.10)$ & $0.96(0.08)$ \\
Fakopp $(\log )$ & 0.54 & $\mathbf{0 . 2 5}(\mathbf{0 . 2 1})$ & $0.00(0.02)$ & $0.99(0.05)$ \\
Hitman $^{\circledR}(\log )$ & 0.61 & 0.85 & $\mathbf{0 . 2 5}(\mathbf{0 . 2 3})$ & $0.99(0.03)$ \\
CSIRO $(\log )$ & 0.60 & 0.87 & $\mathbf{0 . 1 8 ( \mathbf { 0 . 2 0 } )}$ \\
\hline
\end{tabular}

(1) no segregation;

(2) (3\% less Merchant) is a light segregation leading to $2 \%$ extra revenue for MGP12, MGP10 and non-structural material allied with 3\% less revenue for Merchant material;

(3) (5\% less Merchant) is a heavier segregation leading to $2.5 \%$ more revenue than option (2) for MGP12, MGP10 and non-structural material and $5 \%$ less revenue for Merchant material.

Assuming a sawmill capacity of $600000 \mathrm{~m}^{3} \mathrm{y}^{-1}$, this would lead to a net benefit to the sawmill each year of over $\$ 1.5 \mathrm{~m} \mathrm{y}^{-1}$ for option (2) and over $\$ 4 \mathrm{~m} \mathrm{y}^{-1}$ for option (3).

\subsection{Genetic parameters}

The estimates of heritability were mostly little larger than their standard errors (table VI) and so are clearly not very precise estimates and may not be significantly different from 0 . They are much less than heritability estimates for the wood properties density of $0.32\left(\mathrm{se}\left(\mathrm{h}^{2}\right)=0.14\right)$ and cell radial diameter of $0.37\left(\mathrm{se}\left(\mathrm{h}^{2}\right)=0.12\right)$ (Matheson and Evans, unpublished) obtained from the same experiment. Nevertheless, that the genetic correlations are so high suggests that all three acoustic instruments were measuring essentially the same trait in logs and that the tree measurements were slightly different.

\section{DISCUSSION}

This study has found that acoustic sound velocity is a direct measure of wood stiffness in the stems of standing trees or logs of Pinus radiata as it is in other species. There was a significant relationship between machine stress grades and sound velocity in stems of standing trees and logs. The relationship was stronger for the mean stiffness grade values than to the minimum stiffness grade values. This difference may be due to the effect of defects, such as knots, located at specific positions along individual boards. The length of the stress waves was such (probably longer than 1 metre) that they would not have been greatly affected by a localised defect in its travel path and thus were more closely correlated with the mean stress grades of boards for individual logs. The impact of knots and defects was probably reflected more in the stress grades than in sonic velocity values.

The sound velocity measurements recorded across the stems of standing trees and along logs cut from those trees were significantly correlated. However, the velocity across the stems of the standing trees was around half of that recorded along the logs. The reason for this is unclear, but may be a due to the fact that in standing trees the sound waves travelled across (radially) as well as along (longitudinally) the growth layers of the wood, which may have slowed their speed. The standing tree velocity values were also less closely correlated with the board stress grades than the velocity values from logs possibly because they were based on a single measurement per tree (at breast height) rather than several measurements, one for each log up the tree.

Very similar results were obtained in the genetic study with different material. In this case the genetic and phenotypic correlations suggest that the three acoustic tools were giving essentially similar results for logs but were all slightly different from the FAKOPP measurements on standing trees. With an absolute minimum number of samples per family we have shown that heritability is bigger than its standard error in most cases and marginally smaller for the other case. To make use of acoustic tools for indirect selection for stiffness we would have to use larger sample numbers than used here, perhaps 7 or 8 rather than the 6 actually used would be enough [16].

We believe that the relationship between acoustic sound velocity and machine stress grades can be strengthened, particularly either by improved operation of the existing instruments or by development of new equipment. Nevertheless, our findings suggest that acoustic measurements of standing trees and logs offer an opportunity now to predict machine stress grades of sawn lumber. We are aware that new resonance tools are in development, which will be more able to account for the hammer and log dimensional effects on the waveform [14]. However, we argue that the design of similar equipment for the measurement of standing trees is more challenging.

The economic benefits of segregating logs according to sound velocity for both forest growers and sawmillers are significant and are reflected in the outputs of an economic model. There are enormous economic benefits for processors to be had through better allocation of logs, and these are 
directly related to the volumes of the annual harvest. We argue that log segregation is likely to reduce the volume of merchant grade lumber being produced annually leading to a higher proportion of higher value products.

There are three notable opportunities along the wood fibre value chain where forest managers and processors have an opportunity to intervene to improve wood quality. The first intervention point is at the breeding stage [2] where tree breeders may use acoustic tools to test standing trees for stiffness non-destructively and select superior individuals for breeding.

The second intervention point is in the forest, when there is an opportunity to begin the first log segregation step at the time of thinning. Acoustic tools could be used to select standing trees that will yield timber with relatively low stiffness values and mark them to be thinned, thus improving the overall average stiffness of stands. For a production thinning operation, a second segregation, again using acoustics to optimise the use of both thinned and retained material in either the solid wood or reconstituted wood processes.

The third intervention step in the value chain is at the time of harvest when the timber is either sold standing or as logs. In the case of standing trees, acoustic tools could be used to predict the variability in the mechanical performance of standing timber for sale. Considering the extreme variation in wood properties among logs, it will be important to acoustically test them individually and sort them into stiffness classes at either the harvest site or in processing plants.

The challenge at this stage is develop acoustic equipment that is robust enough to operate under both forest and mill conditions and be integrated into mechanical harvesting and merchandising operations.

\section{CONCLUSION}

There was a significant positive relationship between acoustic wave velocity and the timber stiffness in Pinus radiata, which suggests an opportunity to segregate timber while the trees are still standing and to select logs that will yield predominantly high stiffness lumber. The cost of segregation is small and the net benefit to a large sawmill is likely to be several million dollars. The benefits of acoustic tools and log segregation will not be realised until forest growers and processors implement their application in their operations.

Using acoustic methods to select trees indirectly for stiffness for breeding shows promise but would probably need larger numbers of samples per family than used here. The genetic relationship with board stiffness would also have to be demonstrated.

Acknowledgements: This study would not have been possible without the willing cooperation of the IFP sawmill in Canberra and the Weyerhaeuser sawmill at Tumut. The study was funded by CSIRO, State Forests of NSW, IFP and Forest and Wood Products R \& D Corporation. A special thanks to all those who helped in this complex, demanding project; particularly J. Owen, A. Schofield, A. Abarquez and D. Bellingham from CSIRO, I. Hides, B. Joe and C. Wilkinson from SFNSW and the ever helpful staff at the IFP and Weyerhaeuser sawmills.

\section{REFERENCES}

[1] Cown D.J., Corewood (juvenile wood) in Pinus radiata should we be concerned, N. Z. J. For. Sci. 22 (1992) 87-95.

[2] Dickson R.L., Walker J.C.F., Pine: growing commodities or designer trees, Commonw. For. Rev. 76 (1997) 273-279.

[3] Eldridge K.G., Genetic improvements from a radiata pine seed orchard, N. Z. J. For. Sci. 12 (1982) 404-411.

[4] Kaiserlik J.H., Pellerin R.F., Stress wave attenuation as an indicator of lumber strength, Forest Prod. J. 27 (1977) 39-43.

[5] Kempthorne O., An introduction to genetic statistics, Wiley, New York \& London, 1957.

[6] Matheson A.C., Burgess I.P., Gains from breeding Pinus radiata for one generation in Australia, Proc. ANZIF. Rotorua, NZ, 1980.

[7] Matheson A.C., Eldridge K.G., Brown A.G., Spencer D.J., Wood volume gains from first-generation radiata pine seed orchards, CSIRO Division of Forest Research User Series No. 4, 1986, 13 p.

[8] Nakamura N., Arima T., Evaluating the properties of standing trees, Proc Pacific Timber Engineering Conference, July 11-15, 1994, Gold Coast, Australia.

[9] Pine Australia, EG002: An easy guide to MGP Pine, 1998, 3 p.

[10] Pine Australia, Pine Australia Grading Rules for Pine Timber Products, Sixth ed., 1998.

[11] Ross R.J., Geske E.A., Larson G.R., Murphy J.F., Transverse vibration nondestructive testing using a personal computer, Research Paper - Forest Products Laboratory, USDA Forest Service, 1991, No. FPL-RP-502, 17 p.

[12] Ross R.J., McDonald K.A., Green D.W., Schad K.C., Relationship between log and lumber modulus of elasticity, Forest Prod. J. 47(2) (1997) 89-92.

[13] Ross R.R., Using sound to evaluate standing timber, International For. Rev. 1 (1) (1999) 43-44.

[14] Snyder W.D., Kent E.C., Floyd S.L., Jones L.H., Kendall C.K., Pearce B.B., Shaw E., Yancey M.J., Log cutting optimisation, U.S. Patent Application, No. 6026 689, 2000, 12 p.

[15] Walker J.C.F., Nakada R., Understanding corewood in some softwoods: a selective review on stiffness and acoustics, Int. For. Rev. 1 (4) (1999) 251-259.

[16] Raymond C.A., Sampling - Purpose and Cost. Chapter 2, in: Downes G.M., Hudson I.L., Raymond C.A., Dean G.H., Mitchell A.J., Schimleck L.R., Evans R., Muneri A. (Eds.), Sampling Plantation Eucalypts for Wood and Fibre Properties, CSIRO, Collingwood, Australia, 1997. 
